\title{
Jeffrey J. Juris (1971-2020): investigador de los movimientos sociales en red
}

\author{
Carles Feixa ${ }^{1}$ \\ Francisco Ferrándiz ${ }^{2}$ \\ Geoffrey Pleyers ${ }^{3}$ \\ Mayo Fuster Morell ${ }^{4}$ \\ Inếs Pereira ${ }^{5}$ \\ Patricia Oliart ${ }^{6}$
}

Resumen: Jeffrey J. Juris (New Jersey, 1971-Boston, 2020) fue pionero en el estudio del movimiento altermundialista, tema al que dedicó su tesis doctoral, presentada en la Universidad de Berkeley y luego publicada en su influyente libro Networking Futures: the Movements against Corporate Globalization (2008). Ademas de los Estados Unidos, llevó a cabo trabajo de campo en Cataluña y México, a partir de una etnografía transnacional y militante. El artículo repasa la trayectoria de este antropólogo, desaparecido en junio de 2020, a partir del testimonio de personas que coincidieron con él, valorando su contribución al estudio de los movimientos sociales en red.

Palabras clave: Jeffrey J. Juris, movimientos sociales, movimiento antiglobalización, nuevas tecnologías.

\footnotetext{
${ }_{1}^{1}$ Universitat Pompeu Fabra, Barcelona (Cataluña, España).Correo electrónico: carles.feixa@upf.edu

${ }^{2}$ Consejo Superior de Investigaciones Científicas, Madrid. Correo electrónico: francisco.ferrandiz@cchs.csic.es

3 Université de Louvain, Bélgica. Correo electrónico: geoffrey.pleyers@uclouvain.be

4 Universitat Oberta de Catalunya. Correo electrónico: mayo.fuster@eui.eu

5 Universidade Nova de Lisboa. Correo electrónico: ines.pereira@iscte.pt

${ }^{6}$ Newcastle University, UK. Correo electrónico: patricia.oliart@newcastle.ac.uk
} 


\title{
Jeffrey J. Juris (1971-2020): researcher of networked social movements
}

\begin{abstract}
Jeffrey J. Juris (New Jersey, 1971-Boston, 2020) was a pioneer in the study of the antiglobalization movement, a topic to which he dedicated his doctoral thesis, presented at the University of Berkeley and later published in his influential book Networking Futures: the Movements against Corporate Globalization (2008). In addition to the United States, he carried out field work in Catalonia and Mexico, based on a transnational and militant ethnography. The article reviews the trajectory of this anthropologist, who disappeared in June 2020, based on the testimony of people who agreed with him, assessing his contribution to the study of networked social movements.
\end{abstract}

Keywords: Jeffrey J. Juris, social movements, anti-globalization movement, new technologies.

\section{Jeffrey J. Juris (1971-2020): pesquisador dos movimentos sociais em rede}

Resumo: Jeffrey J. Juris (New Jersey, 1971-Boston, 2020) foi um pioneiro no estudo do movimento antiglobalização, tema ao qual dedicou sua tese de doutorado, apresentada na Universidade de Berkeley e posteriormente publicada em seu influente livro Networking Futures: the Movements against Corporate Globalization (2008). Além dos Estados Unidos, realizou trabatho de campo na Catalunha e no México, a partir de uma etnografia transnacional e militante. O artigo revê a trajetória desse antropólogo, desaparecido em junho de 2020, a partir do depoimento de pessoas que concordaram com ele, avaliando sua contribuição para o estudo dos movimentos sociais online.

Palavras-chave: Jeffrey J. Juris, movimentos sociais, movimento antiglobalização, novas tecnologias. 


\section{Jeff Juris, in memoriam}

Durante estos tiempos de pandemia, entre otras muchas personas, nos han dejado dos antropólogos norteamericanos fundamentales para comprender los movimientos sociales en la era digital: David Graeber y Jeffrey J. Juris. El primero, que se hizo famoso en los últimos tiempos con su antropología crítica anarquista, ha fallecido durante el mes de septiembre a los 59 años de edad; el segundo, nos dejó el pasado 18 de junio a los 49 años de edad. Juris - Jeff para los amigoshabía nacido en New Jersey en 1971 en el seno de una familia judía progresista. Tras doctorarse en la Universidad de Berkeley con una tesis sobre el movimiento antiglobalización, realizó una estancia posdoctoral en la University of Southern California bajo la dirección de Manuel Castells, reconocido sociólogo global de las teorías en redes,

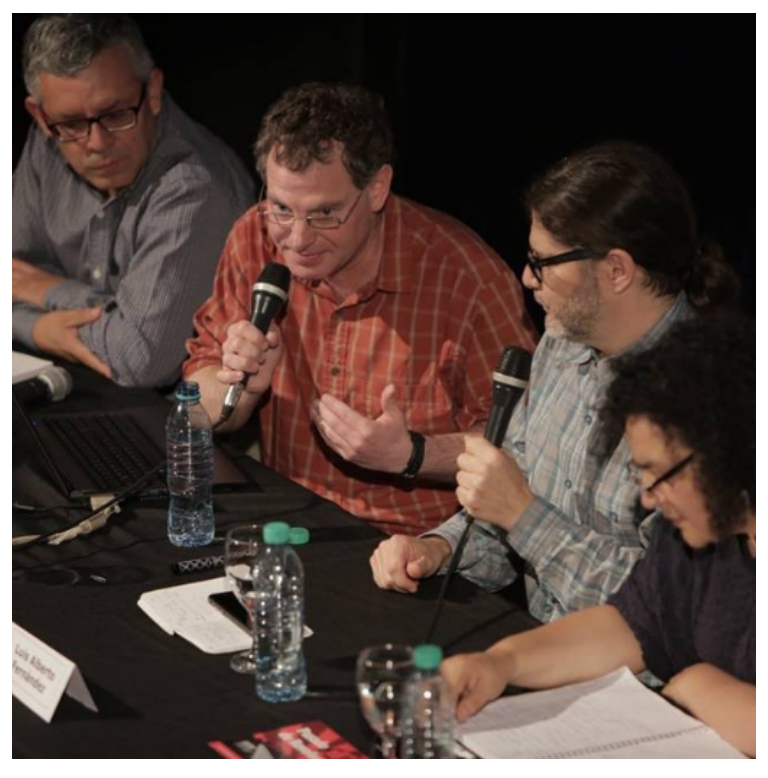
quien lo tenía en su más alta estima. Desde 2009 se dedicó a la docencia y a la investigación en la Northeastern University de Boston. El último año de vida lo pasó luchando contra un cáncer cerebral que resultó letal.

Como se afirma en la nota necrológica de Anthropology News (Martínez-Reyes \& Magaña, 2020), Juris era un investigador muy respetado de los movimientos sociales radicales, centrando su trabajo en investigar cómo los activistas usan la tecnología y los medios para construir redes de movimientos profundos tanto a nivel local como global. Llevó a cabo trabajos de campo en Barcelona, Estados Unidos, México y en numerosas marchas y encuentros activistas internacionales, como los Foros Sociales Mundiales o Europeos (2002, 2005, 2007) y las contracumbres contra el G2o y el Banco Mundial. Jeff también profundizó en una propuesta de una «etnografía militante» donde los métodos objetivistas tradicionales se abandonan en favor de 
formulaciones teóricas y análisis obtenidos a través del compromiso político dentro de los movimientos sociales.

Juris había obtenido una licenciatura con honores en sociología y antropología de la Wesleyan University en 1993. Después de la universidad, se interesó en la política latinoamericana donde empezó a estudiar los movimientos de base mientras trabajaba en proyectos de desarrollo comunitario en Guatemala. En 1995 continuó sus estudios de posgrado en la Universidad de California (Berkeley), mientras trabajaba para una ONG en San Francisco llamada Comité por los Derechos de la Salud en las Américas. Fue en 1999, con el advenimiento de las reuniones de la Organización Mundial del Comercio en Seattle, cuando dirigió su lente antropológica al estudio de los movimientos sociales, no solo como etnógrafo, sino también como activista. Posteriormente acuñaría el término «etnografía militante» como método alternativo de investigación y praxis a partir de su trabajo de campo en Cataluña con los movimientos antiglobalización. Tras recibir su doctorado en Berkeley en 2004, comenzó su carrera docente como profesor asistente de antropología en la Universidad Estatal de Arizona de 2005 a 2008. En ese último año fue investigador invitado en la Universidad Nacional Autónoma de México. En 2009 se mudó a lo que sería su último hogar académico en el Departamento de Sociología y Antropología de la Northeastern University, donde pasó los siguientes once años.

Su obra magna, Networking futures: The movements against corporate globalization (2008), es una etnografía innovadora de las redes de activistas transnacionales dentro de los movimientos contra la globalización corporativa. También es coautor de Global democracy and the World Social Forums (2008) y coeditor de Insurgent encounters: Transnational activism, ethnography, and the political (2013). Su texto «Reflexiones sobre \#Occupy everywhere: Social media, public space, and emerging logics of aggregation» fue el artículo más descargado de American Ethnologist en 2012 y el segundo artículo más descargado de toda la base de datos de AnthroSource ese año. Cuando le sorprendió el cáncer, Juris estaba trabajando en su segundo libro de autoría única, basado en un trabajo de campo en la Ciudad de México sobre radios libres (una manera de viajar hacia el pasado, de la galaxia digital a los primeros medios masivos). Está previsto que Radio libre: medios y autonomía en México aparezca de manera póstuma. Además de ser un experto en movimientos sociales de renombre mundial, Juris fue un generoso mentor y maestro para innumerables estudiantes y colegas. 


\section{Carles Feixa ${ }^{7}$}

Conocí a Jeff en Berkeley hace 25 años, en 1995, por mediación de Francisco Ferrándiz. Viajé con mi mujer Montserrat al campus californiano para realizar una estancia de investigación por invitación de quien después sería director de su tesis: Stanley Brandes. Paco nos acogió y me habló de un antropólogo norteamericano que quería investigar el fútbol en Barcelona. Yo acababa de escribir un texto sobre el Barça y enseguida trabamos amistad. Recuerdo que acudimos juntos a ver un partido en Oakland, rodeados de mexicanos. Jeff había practicado este deporte - lo que en Estados Unidos es una rareza- y quería venir a Cataluña para analizar su relación con el nacionalismo. Como el Barça había sido muy estudiando se inclinaba por el segundo club de Barcelona, el Espanyol, que tras los Juegos Olímpicos estaba en proceso de transformación. El año 2000 publicamos juntos un artículo sobre las football cultures en la revista Social Anthropology (Feixa \& Juris, 200o).

Luego Jeff cambio su tema de tesis, porque como activista le atrapó el movimiento antiglobalización en Seattle de 1999 y consideró con acierto que el tema le había escogido a él. Como mi tema eran los movimientos juveniles, seguimos en contacto. Nos invitó a su boda con su primera mujer valenciana. Cuando vino a Barcelona a realizar trabajo de campo nos encontramos durante las movilizaciones antiglobalización. Recuerdo quedar con él en el claustro de la Universidad de Barcelona, donde conoció a quien luego sería alcaldesa, Ada Colau. Le invité a participar en un foro de juventud en Lleida con jóvenes investigadores que luego tendrían recorrido, como Oscar Aguilera, Mayo Fuster y Yanko González. Con Paco seleccionamos su magnífico texto sobre la revuelta de Génova para el libro Jóvenes sin tregua (Juris, 2005b). Fruto de estos intercambios, en 2009 publicamos con la antropóloga portuguesa Inês Pereira un artículo en la revista Young: «Global citizenship and the new social movements», que ha sido y sigue siendo muy citado (Feixa, Pereira, \& Juris, 2009). En 2016, mientras llevaba a cabo su trabajo de campo sobre radios libres en México, volvimos a coincidir en el zócalo de Coyoacán con su nueva compañera. Cuando surgió el movimiento de los indignados me invitó a participar en un monográfico de la revista Cultural Anthropology que él coordinaba. Luego yo incorporé su magnífico texto sobre «Occupy Boston» en el libro Youth, Space and Time (Juris, 2018).

La última vez que le vi fue durante el último congreso LASA en Barcelona. Cenamos junto a nuestras esposas en un restaurante del Born, tras presenciar una manifestación en pleno proceso

7 Los testimonios que se reproducen a continuación se basan en posts compartidos en Facebook o en textos del documento «Jeff Memories» que su hermana recopiló mediante Google Docs durante sus últimas semanas de vida. Conservan el tono improvisado y emocionado de la redacción original. El texto de Pleyers ha sido expresamente redactado para la ocasión. 
independentista. Hace unos meses prometí enviarle mi último libro El Rey: diario de un Latin King y ahora me sabe mal no haberlo hecho. Cuando supe de su enfermedad me quedé de piedra, porque Jeff estaba en el esplendor de su carrera y se le veía feliz con su mujer Carla y su hijo Sebi. Recuerdo haber hablado de él en un correo electrónico que intercambié con quien fue tribunal de su tesis, Manuel Castells (actual Ministro de Universidades en España) teórico de la sociedad red, cuyo surgimiento Jeff etnografió de forma extraordinaria. Mientras escribo este texto estamos todos confinados y he pensado muchas veces en la sociedad «enredada» que él investigó. Para comprender lo que está pasando estos días volveré a ojear su libro, que tengo en el estante al lado de mi biblioteca.

\section{Francisco Ferrándiz}

Jeff fue uno de mis ángeles guardianes más preciados durante el durísimo programa de doctorado en el Departamento de Antropología de la Universidad de Berkeley al que ambos nos sometimos - al principio sin duda algo indefensos- en los años noventa. Para mí, que me manejaba regular en inglés en aquellos tiempos y que nunca había pisado los Estados Unidos antes, el colectivo de apoyo espontáneo y altruista que construyeron a lo largo del tiempo entre Jeff, Xavier Inda, Matthew Gutmann, Thor Anderson y algunos otros compañeros fue milagroso y es la principal razón de que sobreviviera el programa sin demasiadas heridas. Muchos de los miembros de este colectivo solidario orbitábamos en un círculo algo alejado de las luces de las estrellas del momento en el departamento, en torno a la solvencia y calidez de Stanley Brandes. Stanley nos cohesionó en las inolvidables cenas que organizaba en el jardín de su casa en el downtown de Berkeley, que ya nos ocupábamos de aderezar luego (Jeff entre ellos por supuesto) en algunos de los pubs de la zona, entre ellos el famoso Júpiter.

Por no hablar de las interminables conversaciones que pude compartir con Jeff, a solas o en diferentes constelaciones de doctorandos, ya fuera sobre España, Barcelona, América Latina o las últimas novedades futbolísticas en el mítico Kroeber Hall o paseando por los jardines del campus y la ciudad que lo envolvía (arriba y abajo por la Telegraph Avenue del Hate Man, los street punks y los posjipis; o por el People's Park de los homeless y los runaway kids, con sus carritos de Safeway o sus sacos de dormir, respectivamente; por los vericuetos del campus del Naked Man y las descargas de tambor dominicales). Pero muy especialmente delante de un gigantesco capuchino o un latte en el popularísimo Caffe Strada de College Avenue.

En 1997, cuando salí con mi mujer Chun (ya fallecida también de cáncer hace unos años, y la recién nacida Alba -iya con 23 años!--) hacia Holanda y luego hacia México, en estancias posdoctorales, Jeff fue el custodio de mi biblioteca. Durante el doctorado habíamos visitado innu- 
merables veces las librerías de segunda mano de Telegraph Avenue (MOE's, Shakespeare \& Co.) y sus calles aledañas, comprando de manera compulsiva libros de segunda mano o aquellos que estudiantes con más recursos revendían sin haberlos siquiera abierto. No recuerdo la cantidad de cajas y cajas de libros empaquetados que le dejé a Jeff en su storage place, pero sí que cuando en 1998 volví de Cuernavaca, Morelos, a recogerlos con la intención de instalarnos en México, resulta que hacía unos meses que se había mudado de casa con todas sus cosas..., y toda mi biblioteca. Esa biblioteca adquirida pacientemente en mis años de doctorado, que refleja el momento intelectual que vivimos en Berkeley, es aún mi tesoro académico más preciado. Ahora, sentado en mi despacho del CSIC en Madrid, me tropiezo con ella cada vez que levanto los ojos, ahora más o menos colocados en sus estanterías, y pienso en su historia nómada, en las incontables horas ojeándolos, en las incursiones por las librerías seleccionando o descartando, haciendo cuentas para no gastarme en libros el dinero del alquiler. Y pienso en la generosidad y alegría de vivir que siempre desprendió Jeff y que los impregna a todos.

\section{Geoffrey Pleyers}

Conocí a Jeff en enero del 2005, en un extraordinario encuentro de jóvenes investigadoresactivistas en la selva del sur de Brasil, unos días antes del quinto Foro Social Mundial de Porto Alegre. Me impresionó inmediatamente su fuerte carácter que combinaba un verdadero y profundo compromiso por un mundo más justo con una búsqueda de eficacia en su trabajo como investigador, en las reuniones y en los proyectos activistas. Al año siguiente, él y su esposa Carla me recibieron tres semanas en New Jersey (en una ciudad suburbana cerca de donde él creció) para trabajar en nuestro artículo sobre jóvenes alteractivistas. Me impactó su capacidad de trabajo y su concentración cuando estaba finalizando su libro Networking futures que queda como su obra maestra, así como su atención a cada detalle en los proyectos editoriales individuales o colectivos. Entre 2006 y 2011 nos habíamos convertido en cuates «investigadores-activistas», participando juntos en una serie de contracumbres altermundialistas, protestas y encuentros militantes. Compartimos una carpa para (tratar de) dormir en el frío invierno de Chiapas y bajo el ruido de los helicópteros en el campamento de activistas anti-G8 en el norte de Alemania en el año 2008. Desde entonces, seguimos una larga conversación sobre la autonomía, la democracia y la manera de cambiar el mundo, que retomamos en múltiples encuentros en Ciudad de México, Chiapas, París, Berlín, Boston, Nueva York y en Barcelona durante el congreso LASA de 2018.

Jeff inició la antropología estudiando una tribu de monos, pero pronto cambió de tema para combinar su activismo con sus investigaciones. En los años noventa fue un miembro activo 
de la red People Global Action que se lanzó en Estados Unidos a raíz del levantamiento zapatista. Manejaba cientos de kilómetros para participar en protestas en varias ciudades de California a finales de los noventa y, por supuesto, en las protestas en contra de la Organización Mundial del Comercio en Seattle en 1999. Realizó su principal trabajo de campo y, probablemente, su principal contribución como activista en Barcelona, a principios del decenio de 200o, cuando la ciudad era un punto neurálgico del movimiento altermundialista europeo, combinando las reivindicaciones locales e internacionales con la implementación de alternativas concretas. Después de su doctorado participó activamente en los Foros Sociales de los Estados Unidos, caracterizados por una fuerte participación de las clases populares y de la gente de color. Decidió dedicar su próxima investigación a los medios de información alternativos y en particular a las radios piratas en la Ciudad de México y en América Latina. Participó en varios encuentros zapatistas y quedó muy impactado por la fuerza personal y colectiva de las y los indígenas en sus luchas, como por su propuesta pedagógica.

Como los alteractivistas de los años 2000, a Jeff no le correspondía ninguna etiqueta. No se definía como anarquista, porque consideraba que el anarquismo es un conjunto de prácticas y una perspectiva frente al mundo y a la vida, no una identidad. Se inspiraba mucho por los zapatistas y por prácticas anarquistas y lo que aprendió en sus movimientos sucesivos.

Al mismo tiempo, se insertó con éxito en el mundo académico, encontrando su hogar en Boston. Tenía una capacidad excepcional de combinar en su trabajo de investigación el rigor con la participación activa en los grupos de protesta y debate, así como el compromiso como antropólogo y como activista. Esto se convirtió en el coro de su «etnografía militante», una propuesta metodológica que permanecerá como uno de sus principales legados en el campo de los estudios sobre movimientos sociales. Adoptaba una postura comprehensiva, pero nunca se quedaba pasivo en un movimiento. Como «etnógrafo militante» era obvio para él que no debía (y, en su caso, no podía) quedarse como mero observador, ni en el mundo, ni en la red de activistas que era mucho más que su «trabajo de campo» y de la cual llegaba rápidamente a formar parte, y en algunas ocasiones tener un rol protagónico en sus orientaciones tácticas y sus orientaciones emancipadoras.

Para Jeff, tratar de llegar a un consenso en una reunión de activistas o de resolver problemas entre las diferentes tendencias y opiniones entre los activistas constituía una segunda naturaleza. Jeff era de estas personas que, no solo se preocupa por la igualdad y la justicia a nivel de la sociedad y en sus escritos, sino que lo implementa activamente a su alrededor. Buscaba integrar opiniones y buenas ideas sin dejar de tener su idea de la solución más eficaz o de la táctica que convenía adoptar. 
En la Ciudad de México participó activamente en varias emisiones de radio y se volvió su principal trabajo de campo mientras buscaba conciliar los diferentes grupos de activistas que se quedaron atrapados en peleas internas. Jeff era particularmente bueno en la animación de reuniones abiertas y horizontales; se destacaba por la elaboración de síntesis después de largos encuentros. A menudo se ofrecía como voluntario para moderar reuniones de activistas. Se ponía en una postura abierta sin perder de vista el avance de las discusiones; era capaz de sintetizar los debates de manera que permitían conciliar perspectivas y salir adelante.

La emergencia del «otro mundo posible» al cual aspiraba pasaba por el activismo, las protestas en las cuales Jeff nunca dejó de participar y los proyectos activistas hacia la autonomía o para la difusión de información, un elemento clave en nuestra era como lo mostró uno de sus maestros, Manuel Castells. La batalla para este otro mundo, Jeff también la llevaba en el mundo universitario como profesor e investigador. Dedicaba mucho tiempo a sus clases y a proyectos para sus estudiantes y los jóvenes investigadores que formaba. El mundo académico es un espacio privilegiado para desarrollar, discutir y difundir perspectivas emancipadoras, para pensar juntos y enseñar herramientas para pensar de manera autónoma a sus estudiantes. También es un campo de batalla. En este mundo académico y de la investigación, la obra de Jeff, su manera de actuar y de ser, trazaron nuevas vías y abrieron puertas que permitieron a los jóvenes investigadores de Estados Unidos y de Europa escribir sus tesis de maestría o de doctorado con rigor académico sin dejar de ser activistas, ni tener que esconderlo. Jeff contribuyó a forjar este espacio, por sus convicciones, la edición de un libro colectivo sobre métodos de etnografía activista y, antes que nada, por la calidad de su trabajo, que muestra que el rigor y el compromiso no son por nada opuestos en el trabajo del investigador. Era uno de los miembros más activos de una generación de antropólogos norteamericanos que abrió nuevos espacios para una antropología activista, orientada a la emancipación y la lucha por un mundo menos desigual, cuando esta tradición estaba desacreditada en el mundo académico estadounidense y occidental.

Más allá de ser un activista lleno de energía y convicción, un investigador perspicaz y riguroso y un activista académico, Jeff era un querido amigo y, fundamentalmente, una buena persona. A pesar de la carga que implica el mundo universitario y académico estadounidense, supo dar la importancia a sus amigos y dedicar su tiempo, energía y amor a sus seres más queridos: su hijo Sebi y su esposa Carla. Jeff era un fantástico ser humano que valoraba a cada persona y seguía en su vida el sueño de un mundo donde caben todos los mundos y en el cual cada uno puede encontrar su lugar. En un momento de la pandemia que revela las consecuencias mortales 
de las desigualdades contra las que Jeff siempre luchó, necesitamos que siga siendo una inspiración para otra generación de académicos y activistas, con su convicción y su energía.

\section{Mayo Fuster Morell}

Llevo varios días que me han llegado las tristes noticias respecto a la evolución de Jeff Juris y me ha costado reaccionar; de hecho, aún me invade la incredulidad. Chateamos por su cumpleaños en diciembre y celebramos que, quizás, nos veríamos en verano. Sabía de su enfermedad, pero no me esperaba que pudiera llegar a una situación tan crítica. Varios amigos me han contactado y no es hasta hoy que me he decidido a escribir y contribuir a este bonito homenaje colectivo. Necesitaremos tiempo para hacer esta transición y resituar a Jeff, pero sigue y seguirá estando presente.

Soy amiga de Jeff desde hace 20 años, en una amistad que ha tenido como escenario varios continentes. Nos conocimos en el Movimiento de Resistencia Global en Barcelona en el 2000. El primer recuerdo que tengo es yendo a Génova en 2001 para protestar contra el G8. Fuimos unas 10 personas de avanzadilla de la delegación catalana, junto a Enric Duran, Josep Maria Antentas y Merce Cortina, si recuerdo bien. El primer día dormimos en un centro social a las afueras de Génova, y dormimos bajo una parra, con los portátiles de cojín. Jeff además con sus libretas grandes a modo de diario de campo que siempre le acompañaban. Recuerdo nuestras apasionadas conversaciones en torno a la «Barcelona way», la dinámica de red. Jeff era nuestro puente con Manuel Castells, al que finalmente conocí recientemente y hablamos de Jeff, un querido amigo compartido. Fueron años muy intensos, en que Enric, Jeff y yo estábamos juntos la mayor parte de los días y del día. Fuimos a muchas contracumbres, como a Davos o la de Niza en las que, si recuerdo bien, en ambas le detuvieron; y fundamos Glocal ligado al Infoespai en la Plaza del Sol de Gracia, un espacio de herramientas tecno-políticas.

El 11 de septiembre en que estábamos en casa, Enric y Jeff se fueron a internet a buscar información, y yo me quedé viendo la tele y les llamé al momento de caer la torre. Jeff estaba muy preocupado por su padre y amigos en NYC. Teníamos una grandísima afinidad política en torno a la metáfora política de la red que compartimos con pasión y en català, y a veces con acento mexicano con lo que nos llegaba de inspiración zapatista. Jeff y yo además compartimos antropología, participamos en el Congreso de Estudios de la Juventud en Lleida, que organizó Carles Feixa. También compartimos la voluntad de transformar la investigación y organizamos las Jornadas Investigación de investigación activista por y desde los movimientos sociales en l'Ateneu Nou Barris. Fueron años que nos marcaron para siempre.

Luego Jeff volvió a Estados Unidos, acabó la tesis, y yo me fui a Amsterdam, y nos encontrábamos en el Foro Social Mundial o en eventos internacionales, como el de Betlem o Porto Alegre. 
En el proyecto Networked Politics que impulsamos entre TNI, IGOP y Transform Italia, en 2005 participó en varios de los seminarios que organizamos en tres continentes. Fui a ver a Jeff y conocí a Carla en el periodo en que estuve de estancia en Berkeley y ellos vivían en Fenix. Recuerdo que fuimos a un desierto de cactus en que hacía tanto calor que no se podía estar apenas unos minutos. Años después, volvimos a compartir ciudad en Boston cuando fui a hacer un posdoctorado a Harvard y él era profesor en la Universidad de Boston. Recuerdo cuántas ganas tenía y cuánto hicieron por tener a Sebi. Jeff adelgazó, dejó de tomar café y se alió con el té verde; hacía ejercicio y ifinalmente Sebi llegó! A mí me cogió en Barcelona y le envié una camiseta con un dibujo anarquista y Jeff estaba encantado, decía que era la envidia de su guardería.

Cuando iba a Boston les visitaba en la casa al lado de la colina e iba viendo cómo Sebi crecía. Para mí visitarles era como un oasis, como ir a ver pasar el domingo con familiares. Jeff era la persona en Boston que más conocía y me resultaba más cercana. Un fin de semana fuimos a visitar Bretton Woods, donde se formaron los acuerdos base de la globalización neoliberal; era pleno otoño en New Hampshire, un espectáculo de hojas de todos los colores. Nuestra amistad se nutrió de la experiencia de la paternidad y la maternidad, con la llegada de mi hija Abril.

La última vez que vi a la familia fue en un viaje a Barcelona el año pasado en que organicé una cena en mi casa para que amigos de Jeff en la ciudad pudiéramos verlo y reencontrarnos. Siempre era una alegría verlo, agradable, divertido, con unas salidas humorísticas muy agudas, estimulante, inteligente, cercano, alegre. No puedo creer que no nos vayamos a ver más. Pero tengo muy vivo su recuerdo; y tengo un montón de recuerdos suyos en forma de fotos, escritos conjuntos, amigos comunes. Es de esas personas con las que has vivido experiencias fundacionales en tu vida, has compartido tanto, que sientes una fuerte unión y que es una pieza importante en tu vida. Llego hasta aquí hoy, pero aún tengo un montón de recuerdos y vivencias.

Sebi, cuando quieras venir a Barcelona tendrás una casa y serás bien recibido por Abril (que tiene un poco menos años que tú, pero habéis compartido juegos) como por mí. Tengo un montón de recuerdos de tu padre que me alegrará mucho compartir contigo. Querida Carla, pienso mucho en ti; te mando un fuertísimo abrazo; ojalá pronto te lo pueda dar en persona.

Para la familia antiglobi, es una triste noticia el desenlace de Jeff en este preciso momento, pero de alguna manera hay algo de victoria. Hace poco reflexionaba sobre ello; quién nos lo iba a decir a los antiglobi, 20 años después de las movilizaciones en Seattle y el inicio de siglo; viene un virus global y lleva a reclamar a líderes mundiales; se lleva a cabo parte de las medidas que nosotros reclamábamos en las calles por otra globalización. Qué evento más global que internet y este virus. Cuántas veces a lo largo de estos 20 años he pensado, como cuando llegó el $15 \mathrm{M}$, de cuánta razón teníamos, aunque las nuevas generaciones desconocen la onda por otra globalización y la 
juventud de nuestra generación. Hoy, el mensaje y la lucha del movimiento por la justicia global gana aún más sentido; hoy, libros como el de Jeff, que es uno de los mejores retratos del movimiento global, se hacen más necesarios que nunca.

No me voy a despedir; Jeff seguirá siendo un referente y un gran amigo. Jeff lleva 20 años en mi vida; hay conversaciones y reflexiones sobre otra globalización y cómo las tecnologías pueden apoyar el activismo compartidas entre ambos y, sobre todo, con la trilogía que hacíamos los inseparables Jeff, Enric y yo, que duran 20 años y que seguirán. ¡Hasta la victoria siempre!

\section{Inês Pereira}

Quando eu estava a fazer o meu doutoramento, fui desafiada pelo Carles a apresentar numa aula o texto Violencia representada e imaginada: jóvenes activistas, el Black Bloc y los medios de comunicación en Génova, do Jeff Juris. Este texto sumariava tudo o que eu queria e vim a ser: a etnógrafa-ativista, a fugir de gás lacrimogéneo no meio do maralhal enquanto tomava notas etnográficas. Tive a sorte de, alguns anos depois, ter tocado o altar dos mitos vivos e escrito um artigo com o Carles e o Jeff, que vim depois a conhecer pessoalmente e que, felizmente, era uma pessoa normal e por isso mesmo muito melhor que um mito. O Jeff deixou-nos. Tenho muita pena de não ter tido tempo de me despedir, por causa de um mail que andou perdido numa caixa de correio que pouco uso, numa altura conturbada da minha vida. Mas fico muito feliz de ter tido tempo de lhe dizer o que ele significava para mim, quando apresentei este mesmo texto numa leitura Etno. Urb e o contactei a esse propósito. Cá seguimos, na luta, a celebrar a sua memória.

\section{Patricia Oliart}

Conocí a Jeff en Barcelona. Estábamos esperando el transporte que nos llevaría a una reunión en Lleida, de esas tan bien pensadas y provechosas que organiza Carles Feixa para montar redes efectivas de investigación y colaboración. Gracias a esa avidez de Jeff por beberse cada minuto para alimentar su pensamiento y su militancia, entablamos una rápida y fructífera conversación. Él tenía preguntas muy precisas, escuchaba muy activamente detalles sobre mi investigación sobre colectivos culturales y política en Perú, compartiendo además notas sobre su reciente estadía en México estudiando emisoras de radio pirata, lo que será su libro póstumo Radio libre: Media and autonomy in Mexico. Nos vimos años después en Buenos Aires en 2017. Lo había invitado a presentar una ponencia en una serie de eventos cuya organización apoyé a propósito de la conmemoración del centenario de la Revolución de Octubre. Los eventos estaban montados para explorar de manera muy creativa las nociones de revolución, revuelta, 
subjetividades políticas y militancia. Junto a su buen amigo Luis Alberto Fernández, Jeff presentó una escalofriante ponencia a dos voces. En ella, las milicias fuertemente armadas de extrema derecha en los Estados Unidos aparecían como uno de los retos más grandes para la organización del activismo comunitario con el que Jeff estaba tan militantemente comprometido. Su partida nos deja tareas, pero también la inspiración para seguir pensando y trabajando por el futuro, en tiempos de gran consternación.

\section{Referencias}

Feixa, C., \& Juris, J. S. (2000). Football cultures. Social Anthropology, 8(2), 203-208.

Feixa, C., Pereira, I., \& Juris, J. S. (20o9). Global citizenship and the «new, new» social movements: Iberian connections. Young, $17(4), 421-442$. https://doi.org/frznnr [Trad. castellana: Juris, J. S., Pereira, I., \& Feixa, C. (2012). La globalización alternativa y los novísimos movimientos sociales. Revista del Centro de Investigación, 10(37), 23-39.]

Feixa, C., Saura, J. R., \& Costa, C., (Eds.) (2002). Movimientos juveniles: de la globalización a la antiglobalización. Ariel.

Juris, J. S. (2004a). Networked social movements: Global movements for global justice. En M. Castells (Ed.), The network society: A cross-cultural perspective (pp. 341-62). Edward Elgar. https://doi.org/10.4337/9781845421663.00029

Juris, J. S. (2004b). Digital age activism: Anti-corporate globalization and the cultural politics of transnational networking [Tesis doctoral]. University of California (Berkeley).

Juris, J. S. (2005a). Violence performed and imagined: Militant action, the black bloc, and the mass media in Genoa. Critique of Anthropology, 25(4), 413-32. https://doi.org/ftzw63 [Trad. castellano: Juris, J. S. (2005). Violencia representada e imaginada: jóvenes activistas, el Black Bloc y los medios de comunicación en Génova. En F. Ferrándiz, \& C. Feixa (Eds.), Jóvenes sin tregua: culturas y políticas de la violencia (pp. 185-208). Anthropos.]

Juris, J. S. (2005b). The new digital media and activist networking within anti-corporate globalization movements. The Annals of the American Academy of Political and Social Sciences, 597(1), 189-208. https://doi.org/10.1177/0308275X05058657

Juris, J. S. (2008a). Networking futures: The movements against corporate globalization. Duke University Press.

Juris, J. S. (2008b). Performing politics: Image, embodiment, and affective solidarity during anticorporate globalization protests. Ethnography, 9(1), 61-97. https://doi.org/Cfrah3 
Juris, J. S. (2012). Reflections on \#Occupy everywhere: Social media, public space, and emerging logics of aggregation. American Ethnologist, 39(2), 259-279. https://doi.org/10.1111/ j.1548-1425.2012.01362.x [Reproducido en: Juris, J. S. (2016). Reflections on \#Occupy everywhere: Social media, public space, and emerging logics of aggregation. En C. Feixa, C. Leccardi, \& P. Nilan (Eds.), Youth, space \& time: Agoras and chronotopes in the global city (pp. 385-414). Brill. https://doi.org/10.1163/9789004324589_021]

Juris, J. S., \& Khasnabish, A. (Eds.) (2013). Insurgent encounters. Duke University Press.

Juris, J. S., \& Pleyers, G. H. (2009). Alter-activism: Emerging cultures of participation among young global justice activists. Journal of Youth Studies, 12(1), 57-75. https://doi.org/ $10.1080 / 13676260802345765$

Martínez-Reyes, J., \& Magaña, M. R. (2020, 14 de agosto). Jeffrey S. Juris. Anthropology News. https://www.anthropology-news.org/index.php/2020/o8/14/jeffrey-s-juris/ 